\title{
Circulating Cancer Stem Cells Expressing EpCAM/CD90 in Hepatocellular Carcinoma: A Pilot Study for Predicting Tumor Recurrence after Living Donor Liver Transplantation
}

\author{
Hyeo Seong Hwang ${ }^{1,2}$, Jeong Eun Yoo ${ }^{3}$, Dai Hoon Han ${ }^{1,4,5}$, Jin Sub Choi ${ }^{1,4,5}$, Jae Geun Lee ${ }^{1,5}$, Dong Jin Joo ${ }^{1,5}$, \\ Myoung Soo Kim ${ }^{1,5}$, Soon II Kim ${ }^{1,5}$, Gi Hong Choi ${ }^{1,4,5}$, and Young Nyun Park ${ }^{3,6}$ \\ ${ }^{1}$ Department of Surgery, Yonsei University College of Medicine, Seoul, ${ }^{2}$ Department of Surgery, National Health Insurance Corporation \\ Ilsan Hospital, Goyang, ${ }^{3}$ Department of Pathology, ${ }^{4}$ Yonsei Liver Cancer Special Clinic, ${ }^{5}$ The Research Institute for Transplantation, \\ and ${ }^{6}$ Graduate School of Medical Science, Brain Korea 21 Project, Yonsei University College of Medicine, Seoul, Korea
}

\section{Article Info}

Received April 9, 2021

Revised June 20, 2021

Accepted July 1, 2021

Published online November 5, 2021

\section{Corresponding Author}

Gi Hong Choi

ORCID https://orcid.org/0000-0001-7511-9581

E-mail CHOIGH@yuhs.ac

Young Nyun Park

ORCID https://orcid.org/0000-0003-0357-7967

E-mail young0608@yuhs.ac

Hyeo Seong Hwang and Jeong Eun Yoo contributed equally to this work as first authors.
Background/Aims: Circulating tumor cells (CTCs) with cancer stemness have been demonstrated to be a direct cause of tumor recurrence, and only few studies have reported the role of CTCs in liver transplantation (LT) for hepatocellular carcinoma (HCC).

Methods: Epithelial cell adhesion molecule+ (EpCAM+), cluster of differentiation 90+ (CD90+) and EpCAM+/CD90+ CTCs were sorted via fluorescence-activated cell sorting, and transcripts level of EpCAM, K19 and $C D 90$ in the peripheral blood were analyzed via real-time polymerase chain reaction preoperatively and on postoperative days 1 and 7 in 25 patients who underwent living donor liver transplantation (LDLT) for HCC. EpCAM protein was assessed in HCC tissue using immunohistochemical staining. The median follow-up duration was 40 months.

Results: HCC after LDLT recurred in four out of 25 patients. Detection of EpCAM+ or CD90+ CTCs correlated well with their messenger RNA levels $(p<0.05)$. EpCAM+CTCs were readily detected in HCC tissue expressing EpCAM protein. The detection of EpCAM+ CTCs or EpCAM+I CD90+ CTCs before surgery and on postoperative day 1 was significantly associated with HCC recurrence after $L T$ (all $p<0.05$ ). Pretransplant serum PIVKA-II $>100 \mathrm{mAU} / \mathrm{mL}$ and postoperative day $1 \mathrm{EpCAM+/CD90+CTCs}$ were independent risk factors for $\mathrm{HCC}$ recurrence (hazard ratio, $14.64 ; 95 \%$ confidence interval, 1.08 to $198.20 ; p=0.043$ and hazard ratio, $26.88 ; 95 \%$ confidence interval, 1.86 to $387.51 ; p=0.016$, respectively).

Conclusions: EpCAM+/CD90+ CTCs can be used preoperatively and 1 day after LDLT as key biological markers in LT candidate selection and post-LDLT management. (Gut Liver 2022;16:443-455)

Key Words: Circulating tumor cells; Hepatocellular carcinoma; Liver transplantation

\section{INTRODUCTION}

Liver transplantation (LT) has been the most effective treatment for multicentric, unresectable hepatocellular carcinoma (HCC) since the introduction of the Milan criteria. ${ }^{1}$ However, the Milan criteria, which define macromorphological characteristics of HCC, still implies the risk of HCC recurrence in $10 \%$ to $15 \%$ of patients within the Milan criteria. As a result, high-risk patients within the Mi- lan criteria will receive LT, but those who exceed the Milan criteria and have a low risk of recurrence are excluded from LT candidates. To overcome this limitation, the selection of LT has evolved into Metroticket 2.0 by adding the level of alpha-fetoprotein (AFP) to tumor size and tumor numbers, and further exploring several molecular markers, which can more directly represent tumor biology. ${ }^{2}$ However, given the fact that LT can completely remove the diseased liver as well as tumor lesions, postoperative HCC 
recurrence must be attributed to extrahepatic circulating tumor cells (CTCs), which can disseminate before LT or during surgery. Multiple studies have shown that CTCs are responsible for distant metastasis and postoperative recurrence in many cancers. ${ }^{3-5}$ Recently, a small subset of CTCs with features of stem cells were found to be an actual founder that can contribute to metastasis and recurrence after treatment, in conjunction with the concept of cancer stem cells in tumor tissues. ${ }^{6}$

In HCC, side populations such as cluster of differentiation (CD) 133, keratin 19 (K19), CD90, oval cell marker 6, CD13, CD44, and epithelial cell adhesion molecule (EpCAM) have been demonstrated to have characteristics of cancer stem cells. ${ }^{7,8}$ Among these markers, CD90 and EpCAM were used to detect CTCs with cancer stemness, and were found to show a direct correlation between the numbers of CTCs and HCC recurrence after curative liver resection. ${ }^{9,10}$ We also reported that K19 expression in tumor tissue was more related to tumor aggressiveness and poorer prognosis after surgical resection ${ }^{11}$ and the higher ratio of messenger RNA (mRNA) expression of K19 and $\mathrm{CD} 44$ in peripheral blood during the perioperative period was associated with early recurrence after curative resection. Even though analysis of CTCs with cancer stemness is an appealing method to predict HCC recurrence after LT, only a few studies have addressed this issue so far, and only one study has shown a positive correlation with recurrence after LT. ${ }^{12-14}$

EpCAM and CD90 were selected as representative factors of CTCs in this study because EpCAM is an epithelial stem cell marker and CD90 is a mesenchymal stem cell marker that is expressed on the cell surface. Therefore, fluorescence-activated cell sorting (FACs) of these markers was possible. The presence of EpCAM in tumor cells was associated with high serum AFP levels and poorly differentiated morphology of cancer cells, whereas the presence of CD90, which involves cell-to-cell and cell-to-matrix interactions, indicates that when CD90 is overexpressed in tumors, it promotes cancer dissemination and is associated with a high incidence of distant organ metastasis. ${ }^{15,16}$

In this study, we investigated the role of CTCs in cancer stemness-related genes and their mRNA levels in peripheral blood during the perioperative period to predict HCC recurrence in patients who received living donor liver transplantation (LDLT) for HCC.

\section{MATERIALS AND METHODS}

\section{Patient selection and data collection}

Between April 2014 and March 2017, we prospectively enrolled 25 patients who underwent LDLT for HCC at Severance Hospital, Seoul, Korea. All patients were diagnosed as having HCC via preoperative dynamic liver computed tomography and magnetic resonance imaging. Blood was obtained before starting surgery and at postoperative days 1 and 7. At each time point, $30 \mathrm{~mL}$ of peripheral blood was collected into a BD vacutainer containing $\mathrm{K}_{2}$-EDTA (Becton Dickinson, Franklin Lakes, NJ, USA) for FACs and real-time reverse transcription polymerase chain reaction (RT-qPCR). Five patients presented total tumor necrosis due to preoperative treatments (Table 1), and 20 HCC tissues were examined via immunohistochemical staining (Supplementary Material). All patients were followed up after discharge according to the protocols of our institute. This study was approved by the Institutional Review Board of Severance Hospital, Yonsei University College of Medicine (IRB number: 4-2012-0433). Written informed consent was obtained.

Histopathologic analysis was performed on all resected specimens by routine pathologic examination. The variables included tumor markers, tumor size, differentiation according to Edmondson-Steiner grade, multiplicity of tumors, microvascular invasion (MVI), and pathology details of non-tumor liver tissue were obtained from a review of medical records.

Patients were 38 to 65 years of age (median age 56) and consisted of 23 males and two females. The median followup time after transplantation was 39.50 months (range, 7.37 to 59.80 months). Twenty-two cases were hepatitis B virusrelated, and the remainder were hepatitis $C$ virus-related $(n=1)$ or non- $B$, non-C hepatitis $(n=2)$. Twenty patients received preoperative treatments. Twelve patients (48\%) were initially above the Milan criteria. Of the 25 patients, five patients had undergone successful locoregional therapy to be downstaged within the Milan criteria before LDLT.

HCC recurrence after LDLT was observed in four patients (16\%) during follow-up, a median of 38.63 months (range, 1.6 to 59.8 months), and two out of four patients received calcineurin inhibitor $(\mathrm{CNI})$ with mammalian target of rapamycin inhibitor (mTORi), and the remaining patients were prescribed CNI with mycophenolate mofetil (MMF). Sorafenib was administered to all four patients with recurrence, of whom three patients underwent either metastatectomy or other locoregional therapy. Two patients started taking sorafenib after adrenalectomy and transarterial chemoembolization, respectively and showed stable disease until the last follow-up. One patient presented progress disease after combined treatments of sorafenib and locoregional treatment and the last patient was transferred to hospice care center after treated with sorafenib because of multiple lung, distal common bile duct, and 
Table 1. Patient Baseline Clinicopathological Characteristics

\begin{tabular}{|c|c|}
\hline Characteristics & Total (n=25) \\
\hline Age, median (range), yr & $56(38-65)$ \\
\hline \multicolumn{2}{|l|}{ Sex } \\
\hline Male & $23(92)$ \\
\hline Female & $2(8)$ \\
\hline \multicolumn{2}{|l|}{ Etiology } \\
\hline HBV & $22(88)$ \\
\hline $\mathrm{HCV}$ & $1(4)$ \\
\hline NBNC & 2 (8) \\
\hline \multicolumn{2}{|l|}{ Child-Pugh class at LT } \\
\hline A & $14(56)$ \\
\hline $\mathrm{B}$ & $6(24)$ \\
\hline C & $5(20)$ \\
\hline MELD scores at LT, median (range) & $8(6-25)$ \\
\hline \multicolumn{2}{|l|}{ Pretransplant serum AFP } \\
\hline$<400 \mathrm{ng} / \mathrm{mL}$ & $24(96)$ \\
\hline$\geq 400 \mathrm{ng} / \mathrm{mL}$ & $1(4)$ \\
\hline \multicolumn{2}{|l|}{ Pretransplant serum PIVKA-II } \\
\hline$<100 \mathrm{mAU} / \mathrm{mL}$ & $17(68)$ \\
\hline$\geq 100 \mathrm{mAU} / \mathrm{mL}$ & 8 (32) \\
\hline \multicolumn{2}{|l|}{ Cirrhosis } \\
\hline Yes & $20(80)$ \\
\hline No & $5(20)$ \\
\hline \multicolumn{2}{|l|}{ Milan criteria } \\
\hline Within & 18 (72) \\
\hline Beyond & $7(28)$ \\
\hline \multicolumn{2}{|l|}{ BCLC staging system at LT } \\
\hline 0 & $4(16)$ \\
\hline A & 8 (32) \\
\hline B & $9(36)$ \\
\hline C & $4(16)$ \\
\hline \multicolumn{2}{|l|}{ UNOS staging classification at LT } \\
\hline I & $13(52)$ \\
\hline$\|$ & $5(20)$ \\
\hline III & $4(16)$ \\
\hline IV & $3(12)$ \\
\hline \multicolumn{2}{|l|}{ Pretransplant treatment } \\
\hline Liver resection & $5(20)$ \\
\hline TACE & $11(44)$ \\
\hline RFA & $1(4)$ \\
\hline Radioembolization & $1(4)$ \\
\hline CCRT & $2(8)$ \\
\hline No pretransplant treatment & $5(20)$ \\
\hline \multicolumn{2}{|l|}{$\mathrm{MVI}$} \\
\hline Yes & $6(24)$ \\
\hline No & $19(76)$ \\
\hline \multicolumn{2}{|l|}{ Edmondson-Steiner grade } \\
\hline I-II & $12(48)$ \\
\hline III-IV & $9(36)$ \\
\hline NA & $4(16)$ \\
\hline \multicolumn{2}{|l|}{ Post-transplant usage of mTORi } \\
\hline Yes & $16(74)$ \\
\hline No & $9(36)$ \\
\hline Follow-up period, median (range), mo & $39.50(7.37-59.80)$ \\
\hline
\end{tabular}

Data are presented as the number (\%) unless otherwise indicated. $\mathrm{HBV}$, hepatitis B virus; $\mathrm{HCV}$, hepatitis C virus; NBNC, non-B, non-C hepatitis; LT, liver transplantation; MELD, Model for End-Stage Liver Disease; AFP, alpha-fetoprotein; PIVKA-II, protein induced by vitamin K absence-II; BCLC, Barcelona Clinic Liver Cancer; UNOS, United Network for Organ Sharing; TACE, transarterial chemoembolization; RFA, radiofrequency ablation; CCRT, concurrent chemoradiotherapy; MVI, microvascular invasion; NA, not available; mTORi, mammalian target of rapamycin inhibitor. bone metastasis without further evaluation.

\section{Immunosuppressive agents}

Cumulative dosages of immunosuppressant drugs were administered after transplantation based on the association of a CNI (tacrolimus or Prograf) and corticosteroids according to the immunosuppressant protocol employed at our hospital. Of the 25 patients, 13 patients were switched from MMF to everolimus within one month after surgery. In five patients, MMF was slowly changed to everolimus according to patient condition and the presence of biliary complications. Six patients took MMF and one patient did not use MMF or mTORi. Of the four recurrent patients, two were taking mTORi before HCC recurrence and continued to take it even after relapse. In the other two patients, MMF was switched to mTORi after HCC recurrence. Corticosteroid was added to immunosuppressant drugs for all 24 patients except one.

\section{Flow cytometry}

As mononuclear cells and CTCs were located in the same layer, mononuclear cells and CTCs were isolated from the $10 \mathrm{~mL}$ blood sample using density gradient centrifugation before FACs analysis. Briefly, $10 \mathrm{~mL}$ of blood was diluted with an equal volume of phosphate-buffered saline solution (Gibco, Grand Island, NY, USA) and layered onto Ficoll-Paque ${ }^{\mathrm{TM}}$ PLUS (GE Healthcare Bioscience, Pittsburgh, PA, USA) and centrifuged at 2,000 $\times g$ for 20 minutes at $25^{\circ} \mathrm{C}$. Thereafter, the layer of mononuclear cells was transferred to a new tube and washed.

The isolated cells were labeled with mouse-anti-human CD45-FITC, CD326 (EpCAM)-APC, and CD90-PE antibodies (Miltenyi Biotech Inc., Auburn, CA, USA). A combination of CD45- and CD90+ was used to define nonlymphatic CD90+ cells in the circulation. Labeled cells were detected via FACs using FACSCalibur (Becton Dickson Immunocytometry Systems, San Jose, CA, USA). Suitable isotypes of unrelated antibodies were used as negative controls. Blood specimens were processed approximately 2 hours after collection. The first gating was in the large cell region. After excluding CD45+ cells, CD45-/CD326+/ CD90-, CD45-/CD326-/CD90+, and CD45-/CD326+/ CD90+ cells were identified and counted in the CD45population (Fig. 1).

\section{Statistical analysis}

All continuous data are reported as medians (range). The Mann-Whitney U test was used to compare continuous data, and the Fisher exact test was used to analyze categorical variables. The Pearson correlation coefficient was used to compare the amounts of CTCs and mRNA 

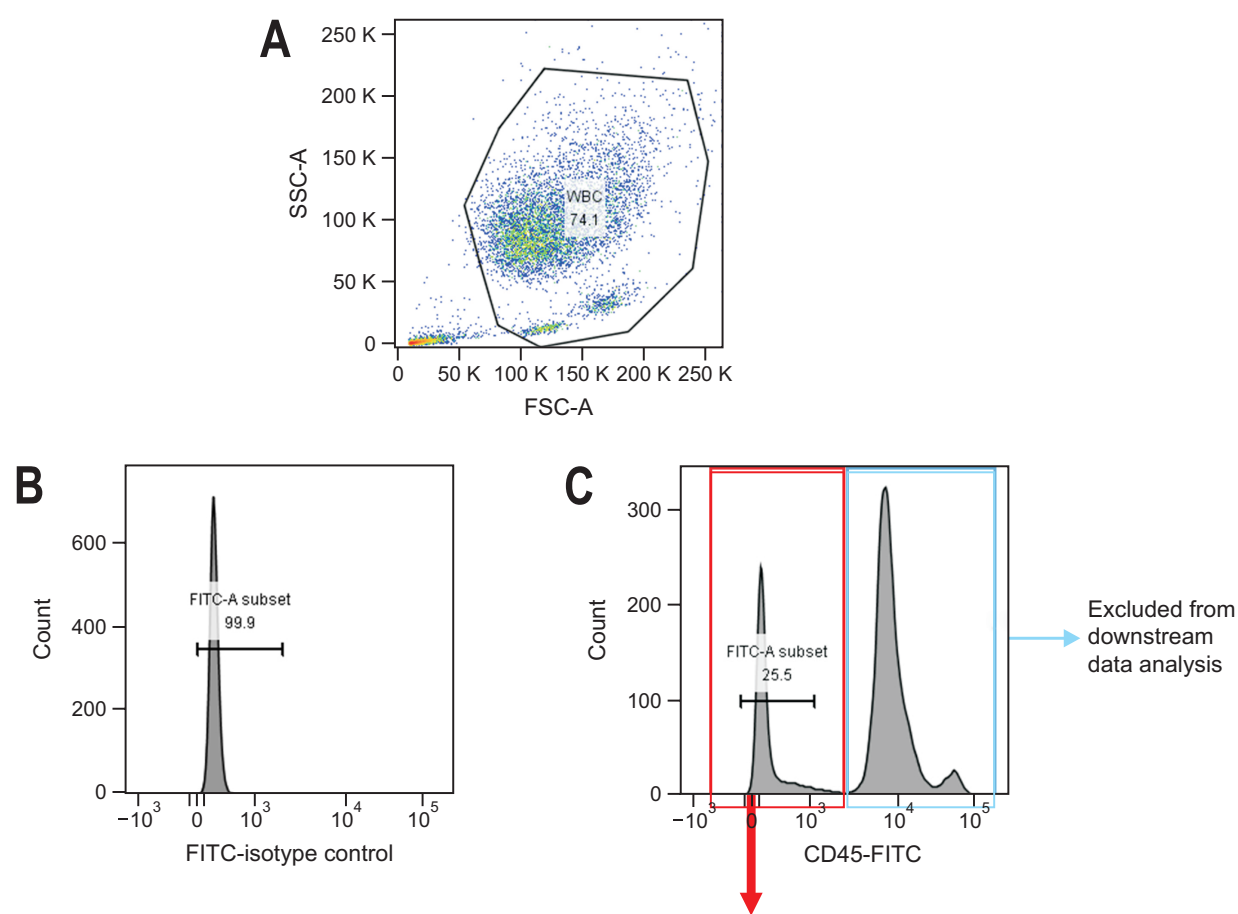

Fig. 1. Example of flow cytometry data analysis. The strategy followed to exclude hematopoietic cells with anti-CD45-FITC antibody is shown. (A) Forward scatter versus side scatter (FSC-A vs SSC-A) plot for total counted events; the gate excludes cell doublets and very large cells. (B) Histogram of isotype control using cells within the defined gate (A). (C) Cells within the defined gate $(A)$ are represented in

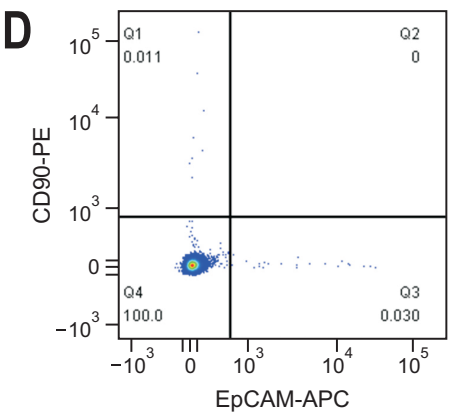
a histogram to evaluate the relative expression of CD45-FITC. (D) Cell counting was based on the expression of either EpCAM or CD90 in the triple-stained samples using CD45 negative cell population (red box in C).

WBC, white blood cell; CD, cluster of differentiation; FITC, fluorescein isothiocyanate; EpCAM, epithelial cell adhesion molecule.

levels of stemness- and epithelial-mesenchymal transition (EMT)-related genes. The primary endpoint of this study was determining the correlation between diseasefree survival (DFS) and isolated perioperative CTCs with cancer stemness from peripheral blood using FACs. DFS was calculated using the Kaplan-Meier method and the Cox proportional hazards model, and differences were compared using the log-rank test. All statistical analyses were performed using the statistical software SPSS version 23.0 for Windows (IBM Corp., Armonk, NY, USA), with $\mathrm{p}<0.05$ considered statistically significant. Receiver operating characteristic curve was employed to identify optimal cutoff levels for CTC counts using the MedCalc program version 12.7.0 (MedCalc Software, Ostend, Belgium).

\section{RESULTS}

\section{Clinicopathological characteristics of HCCs according to the expression status of EpCAM and/or CD90}

Peripheral blood samples were collected from 25 patients with HCC who underwent LDLT before surgery and at postoperative days 1 and 7, and then, EpCAM+, CD90+, and EpCAM+/CD90+ CTCs were detected via FACs. In the blood samples before surgery, the average number of EpCAM+, CD90+, and EpCAM+/CD90+ CTCs were 10.25 (range, 1 to 37 ), 4.40 (range, 1 to 14 ) and 4.83 (range, 1 to 14 ), respectively. On postoperative day 1 , the average number of EpCAM+, CD90+, and EpCAM+/CD90+ CTCs were 12.60 (range, 1 to 71 ), 4.60 (range, 1 to 18 ) and 1.83 (range, 1 to 4), respectively. On postoperative day 7 the average number of EpCAM+, CD90+, and EpCAM+l CD90+ CTCs were 4.69 (range, 1 to 15), 2.78 (range, 1 to 8), and 2.00 (range, 1 to 4), respectively. EpCAM, CD90 and co-expressed CTCs ( $\geq 1$ per $10 \mathrm{~mL}$ blood) before surgery were detected in $12(48 \%), 10(40 \%)$, and six $(24 \%)$ 

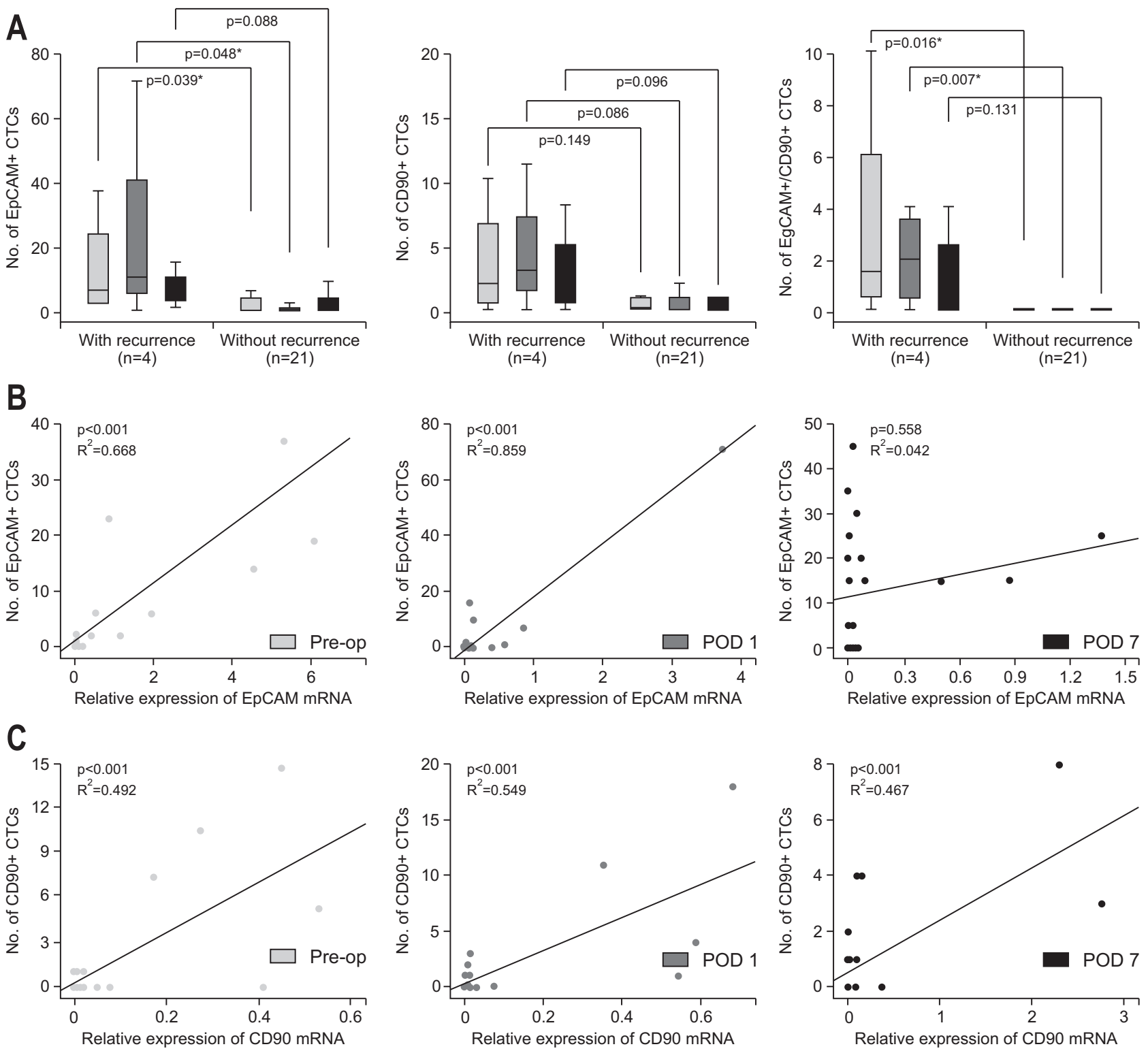

Fig. 2. Comparison of the number of circulating tumor cells (CTCs) with and without recurrence. Comparison of the number of CTCs expressing either EpCAM or CD90 and coexpressing EpCAM and CD90 in hepatocellular carcinoma patients with and without recurrence, on postoperative days 1 and 7 (A). The correlation between the number of CTCs expressing EpCAM and EpCAM mRNA levels is shown preoperatively and on postoperative days 1 and 7 (B). Dot blot showing the correlation with the number of CTCs expressing CD90 and mRNA levels of CD90 preoperatively and on postoperative days 1 and 7 (C).

EpCAM, epithelial cell adhesion molecule; CD, cluster of differentiation; Pre-op, preoperative; POD, postoperative day; mRNA, messenger RNA.

patients, respectively. On postoperative day 1, EpCAM+, $\mathrm{CD} 90+$, and EpCAM+/CD90+ CTCs were detected in $11(44 \%), 11$ (44\%), and six (24\%) patients, respectively. On postoperative day 7, EpCAM+ or CD90+ CTCs were detected in $16(64 \%)$ and nine (36\%) patients, and EpCAM+/CD90+ CTCs were identified in five (20\%) patients (Supplementary Table 1). Through plotting a receiver operating characteristic curve, the optimal cutoff level of
CTC counts, which represents the maximum sum of the sensitivity and specificity for predicting HCC recurrence, was found to be 1 (Supplementary Fig. 1).

The number of EpCAM+ CTCs in HCC patients with recurrence was significantly higher than in HCC patients without recurrence preoperatively (mean, 12.75 vs $3.79 ; \mathrm{p}=0.039)$ and on postoperative day 1 ( 22.75 vs 1.90 ; $\mathrm{p}=0.048$ ), whereas this difference was not significant by 
postoperative day 7 (6.50 vs 2.53; $\mathrm{p}=0.088$ ) (Fig. 2A left). The counts of CD90+ CTCs showed no significant difference between HCC patients with recurrence and those without preoperative, on postoperative days 1 and 7 (all $\mathrm{p}>0.05$ ) (Fig. 2A middle). The number of EpCAM+l CD90+ CTCs in HCC with recurrence was significantly greater than that in HCC without recurrence preoperatively ( 3.25 vs $0.84 ; \mathrm{p}=0.016$ ) and on postoperative day 1 ( 2.00 vs $0.16 ; \mathrm{p}=0.007$ ), but not on postoperative day 7 ( 1.25 vs $0.28 ; \mathrm{p}=0.131$ ) (Fig. 2A right).

Potential correlations involving the detected numbers of EpCAM+ CTCs and levels of EpCAM mRNA in peripheral blood were also investigated. We found that the number of detected EpCAM+ CTCs was well matched with the mRNA levels of EpCAM in CD45-depleted peripheral blood mononuclear cells $\left(\mathrm{R}^{2}=0.668, \mathrm{p}<0.001\right)$ on postoperative day $1\left(R^{2}=0.859, p<0.001\right)$, but not on postoperative day $7\left(\mathrm{R}^{2}=0.042, \mathrm{p}=0.558\right)$ (Fig. $\left.2 \mathrm{~B}\right)$. The mRNA levels of CD90 in CD45-depleted peripheral blood mononuclear cells was strongly correlated with the number of CD90+ CTCs preoperatively $\left(\mathrm{R}^{2}=0.467, \mathrm{p}<0.001\right)$, on postoperative day $1\left(R^{2}=0.549, p<0.001\right)$, and on postoperative day 7 $\left(\mathrm{R}^{2}=0.492\right.$, $\left.\mathrm{p}<0.001\right)$ (Fig. 2C).

Significant correlation of EpCAM+/CD90+ CTCs with MVI compared to cells expressing either EpCAM or CD90 alone or not preoperative, on postoperative days 1 and 7 (50.0\%, 66.7\%, and $60.0 \%$ were positive for MVI, with $\mathrm{p}=0.087, \mathrm{p}=0.005$, and $\mathrm{p}=0.035$, respectively), and higher
A

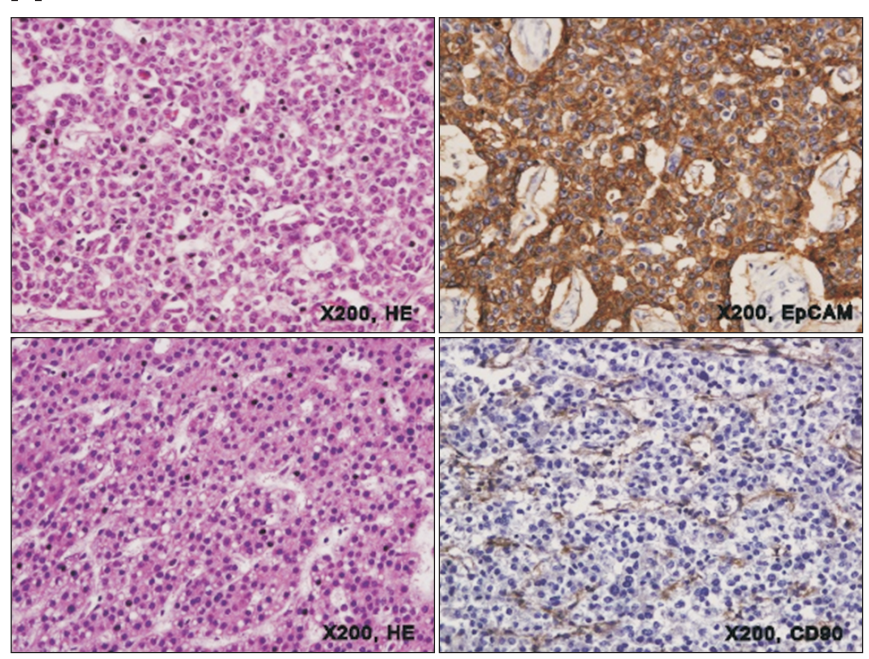

B
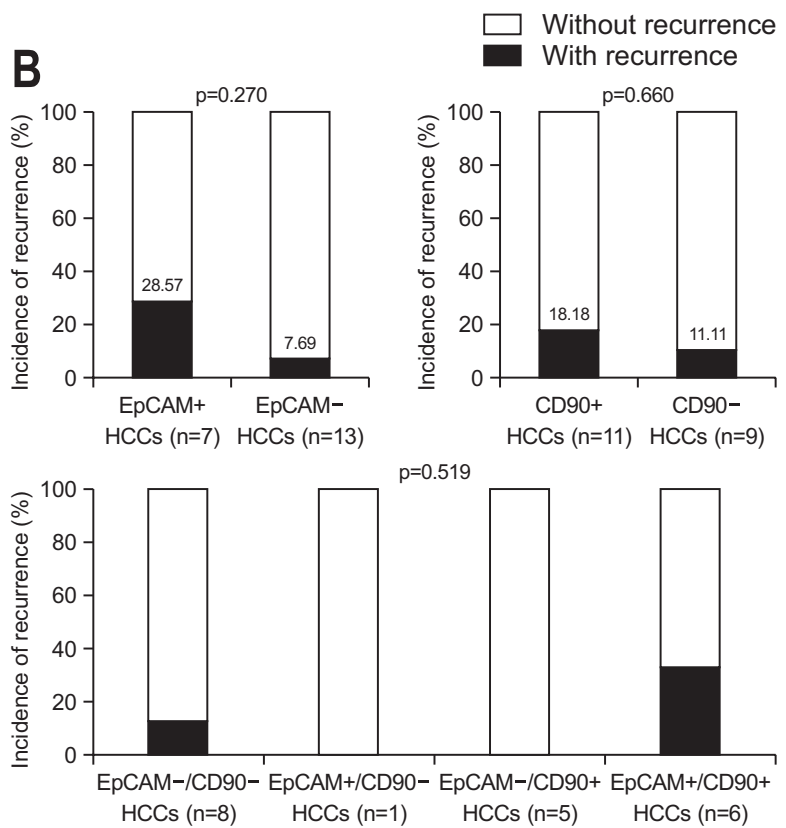
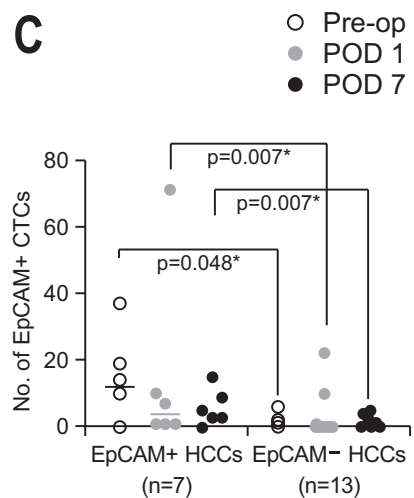

O Pre-op

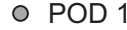

- POD 7
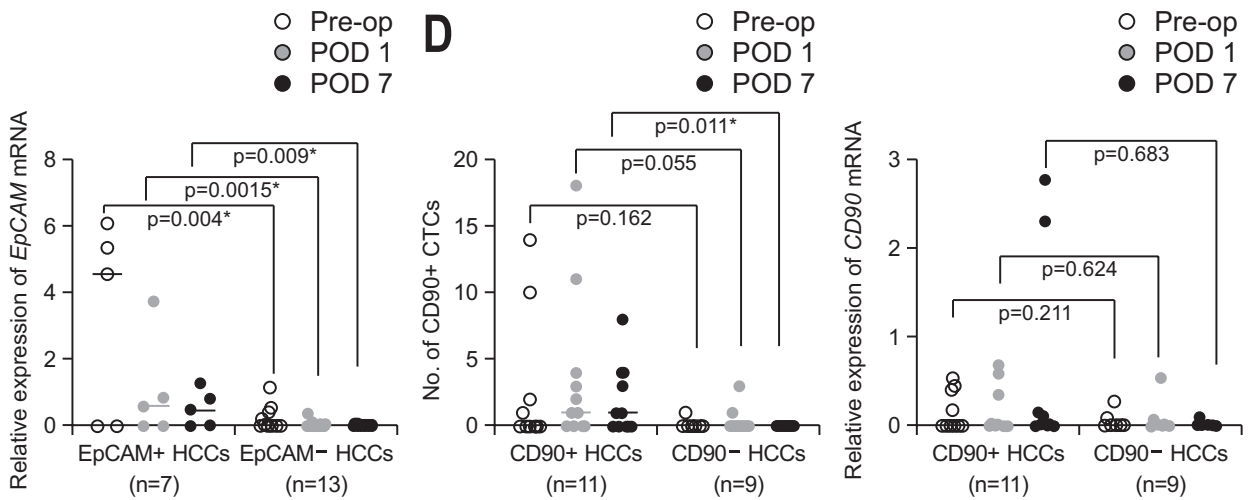

Fig. 3. Comparison of EpCAM-positive circulating tumor cells (CTCs) and mRNA levels of EpCAM according to the status of EpCAM expression in HCC tissues. (A) Representative images of EpCAM and CD90 expression (right, $\times 200$ ) and H\&E (left, $\times 200)$ in HCC. (B) Bar chart showing the incidence of recurrence according to EpCAM, CD90, EpCAM/CD90 detection in HCC tissue. Differences in EpCAM-expressing CTC numbers (C) and CD90-expressing CTC numbers (D) according to the respective EpCAM or CD90 protein expression status in HCC tissues assessed preoperatively and on postoperative days 1 and 7.

EpCAM, epithelial cell adhesion molecule; mRNA, messenger RNA; HCC, hepatocellular carcinoma; CD90, cluster of differentiation 90; Pre-op, preoperative; POD, postoperative day. ${ }^{*} \mathrm{p}<0.05$. 
correlation of Child-Pugh class with EpCAM+ CTCs on postoperative day $1(\mathrm{p}=0.023)$ were observed, but not with other clinical characteristics, such as age, gender, etiology, Model for End-Stage Liver Disease score, preoperative serum AFP $>400 \mathrm{ng} / \mathrm{mL}$, preoperative serum protein induced by vitamin $\mathrm{K}$ absence-II (PIVKA-II) >100 mAU/ $\mathrm{mL}$, Milan criteria, Barcelona Clinic Liver Cancer stage at LT, United Network for Organ Sharing stage at LT, pretransplant treatment, or pathologic Edmondson-Steiner grade (all $\mathrm{p}>0.05$ ) (Supplementary Table 2).

\section{Comparison of EpCAM+/CD90+ CTCs and EpCAM/ CD90 mRNA levels in peripheral blood according to EpCAM/CD90 protein expression status in HCCs}

Immunohistochemical staining for EpCAM and CD90 was performed in surgically removed human HCC tissues (Fig. 3). The recurrence was compared to the status of EpCAM and/or CD90 expression of HCCs. EpCAM protein was expressed in seven of 20 (35.0\%) HCCs (Fig. 3B). Two of EpCAM expressed HCCs were shown pantumoral expression, while two patients were peritumoral EpCAM expression. The remaining three cases were shown focal expression of EpCAM without specific pattern in the intratumoral region (Supplementary Fig. 2). Two out of seven EpCAM+ HCCs recurred (28.57\%), and one recurred in 13 EpCAM- HCCs (7.69\%) (Fig. 3B). However, the pattern of EpCAM expression was not associated with the recurrence. Moreover, the number of EpCAM+ CTCs counted by FACs was statistically higher in EpCAM+ HCCs than in those without expression of EpCAM protein, and this statistical difference was identified in preoperative and postoperative day 1 samples, and postoperative day 7 samples (all p<0.05) (Fig. 3C). EpCAM transcripts were higher in EpCAM+ HCCs than in EpCAM- HCCs (all p<0.05) (Fig. $3 \mathrm{C})$.

The expression of CD90 was detected in the stellate cells of HCCs and eleven (55\%) out of 20 HCCs showed CD90 expression (Fig. 3). There was no significant difference of CD90 expression between HCCs with recurrence and those without recurrence. The number of CD90+ CTCs counted

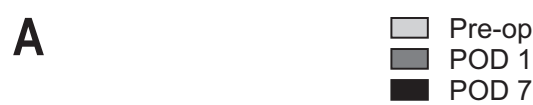

B
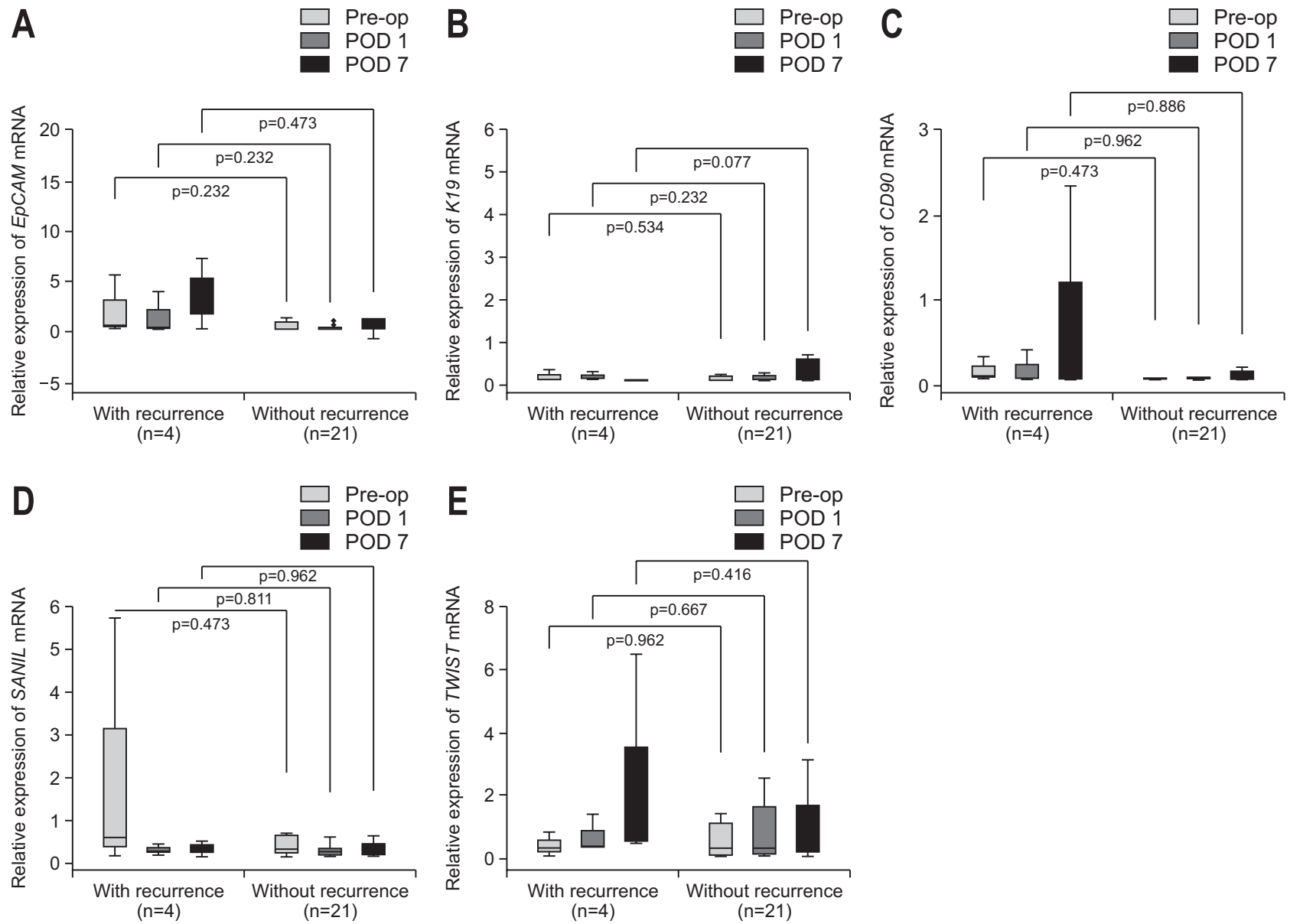

Fig. 4. Differences in the mRNA levels of stemness- and EMT-related genes in patients with and without recurrence. Box plot showing the mRNA levels of (A) EpCAM, (B) K19, (C) CD90, (D) SNAIL, and (E) TWIST preoperatively and at postoperative days 1 and 7. mRNA, messenger RNA; EMT, epithelial-mesenchymal transition; EpCAM, epithelial cell adhesion molecule; K19, keratin 19; CD90, cluster of differentiation 90; Pre-op, preoperative; POD, postoperative day. 
Table 2. Univariate Analysis of Factors Predictive of Recurrence or Disease-Free Survival

\begin{tabular}{|c|c|c|c|c|c|}
\hline \multirow{2}{*}{ Characteristics } & \multirow{2}{*}{$\begin{array}{l}\text { No. of patients } \\
\text { (recurrence) }\end{array}$} & \multicolumn{3}{|c|}{ Disease-free survival, \% } & \multirow{2}{*}{ p-value } \\
\hline & & 1 Year & 3 Years & 5 Years & \\
\hline Age & & & & & 0.620 \\
\hline$\leq 50 \mathrm{yr}$ & $4(1)$ & 75.0 & 75.0 & 75.0 & \\
\hline$>50 \mathrm{yr}$ & $21(3)$ & 90.5 & 85.7 & 85.7 & \\
\hline Sex & & & & & 0.541 \\
\hline Male & $23(4)$ & 87.0 & 82.6 & 82.6 & \\
\hline Female & $2(0)$ & 100.0 & 100.0 & 100.0 & \\
\hline Etiology & & & & & 0.396 \\
\hline HBV & $22(3)$ & 90.9 & 86.4 & 86.4 & \\
\hline $\mathrm{HCV}$ & $1(0)$ & 100.0 & 100.0 & 100.0 & \\
\hline NBNC & $2(1)$ & 50.0 & 50.0 & 50.0 & \\
\hline Cirrhosis & & & & & 0.298 \\
\hline Yes & $20(4)$ & 85.0 & 80.0 & 80.0 & \\
\hline No & $5(0)$ & 100.0 & 100.0 & 100.0 & \\
\hline Pretransplant liver operation & & & & & 0.094 \\
\hline Yes & $5(2)$ & 60.0 & 60.0 & 60.0 & \\
\hline No & $20(2)$ & 95.0 & 90.0 & 90.0 & \\
\hline Milan criteria & & & & & 0.289 \\
\hline Within & $18(2)$ & 88.9 & 88.9 & 88.9 & \\
\hline Beyond & $7(2)$ & 85.7 & 71.4 & 71.4 & \\
\hline Pretransplant serum AFP & & & & & 0.673 \\
\hline$\geq 400 \mathrm{ng} / \mathrm{mL}$ & $1(0)$ & 100.0 & 100.0 & 100.0 & \\
\hline$<400 \mathrm{ng} / \mathrm{mL}$ & $24(4)$ & 87.5 & 83.3 & 83.3 & \\
\hline Pretransplant serum PIVKA-II & & & & & $0.047^{*}$ \\
\hline$\geq 100 \mathrm{mAU} / \mathrm{mL}$ & $8(3)$ & 75.0 & 62.5 & 62.5 & \\
\hline$<100 \mathrm{mAU} / \mathrm{mL}$ & $17(1)$ & 94.1 & 94.1 & 94.1 & \\
\hline Preoperative EpCAM+ & & & & & $0.025^{*}$ \\
\hline Yes & $12(4)$ & 75.0 & 66.7 & 66.7 & \\
\hline No & $13(0)$ & 100.0 & 100.0 & 100.0 & \\
\hline POD 1 EpCAM+ & & & & & 0.156 \\
\hline Yes & $11(3)$ & 72.7 & 72.7 & 72.7 & \\
\hline No & $14(1)$ & 92.9 & 92.9 & 92.9 & \\
\hline POD 7 EpCAM+ & & & & & 0.114 \\
\hline Yes & $16(4)$ & 81.3 & 75.0 & 75.0 & \\
\hline No & $9(0)$ & 100.0 & 100.0 & 100.0 & \\
\hline Preoperative EpCAM+/CD90+ & & & & & $0.004^{*}$ \\
\hline Yes & $6(3)$ & 50.0 & 50.0 & 50.0 & \\
\hline No & $19(1)$ & 94.7 & 94.7 & 94.7 & \\
\hline POD 1 EpCAM+/CD90+ & & & & & $0.004^{*}$ \\
\hline Yes & $6(3)$ & 50.0 & 50.0 & 50.0 & \\
\hline No & $19(1)$ & 100.0 & 94.7 & 94.7 & \\
\hline POD 7 EpCAM+/CD90+ & & & & & 0.077 \\
\hline Yes & $5(2)$ & 60.0 & 60.0 & 60.0 & \\
\hline No & $20(2)$ & 95.0 & 90.0 & 90.0 & \\
\hline Preoperative CD90+ & & & & & 0.104 \\
\hline Yes & $10(3)$ & 70.0 & 70.0 & 70.0 & \\
\hline No & $15(1)$ & 100.0 & 93.3 & 93.3 & \\
\hline POD 1 CD90+ & & & & & 0.156 \\
\hline Yes & $11(3)$ & 72.7 & 72.7 & 72.7 & \\
\hline No & $14(1)$ & 100.0 & 92.9 & 92.9 & \\
\hline POD 7 CD90+ & & & & & 0.083 \\
\hline Yes & 9 (3) & 77.8 & 66.7 & 66.7 & \\
\hline No & $16(1)$ & 93.8 & 93.8 & 93.8 & \\
\hline MVI & & & & & 0.519 \\
\hline Yes & $6(2)$ & 66.7 & 66.7 & 66.7 & \\
\hline No & $19(2)$ & 93.3 & 86.7 & 86.7 & \\
\hline
\end{tabular}




\begin{tabular}{|c|c|c|c|c|c|}
\hline \multirow{2}{*}{ Characteristics } & \multirow{2}{*}{$\begin{array}{l}\text { No. of patients } \\
\text { (recurrence) }\end{array}$} & \multicolumn{3}{|c|}{ Disease-free survival, \% } & \multirow{2}{*}{$\mathrm{p}$-value } \\
\hline & & 1 Year & 3 Years & 5 Years & \\
\hline Tumor size & & & & & 0.498 \\
\hline$\leq 5 \mathrm{~cm}$ & $19(4)$ & 84.2 & 78.9 & 78.9 & \\
\hline$>5 \mathrm{~cm}$ & $2(0)$ & 100.0 & 100.0 & 100.0 & \\
\hline Tumor number & & & & & 0.262 \\
\hline Single & $6(2)$ & 83.3 & 66.7 & 66.7 & \\
\hline Multiple & $17(2)$ & 88.2 & 88.2 & 88.2 & \\
\hline Edmondson-Steiner grade & & & & & 0.713 \\
\hline I-II & $12(2)$ & 91.7 & 83.3 & 83.3 & \\
\hline III-IV & $9(2)$ & 77.8 & 77.8 & 77.8 & \\
\hline NA & $4(0)$ & & & & \\
\hline Post-transplant usage of mTORi & & & & & 0.466 \\
\hline Yes & $16(2)$ & 93.8 & 87.5 & 87.5 & \\
\hline No & 9 (2) & 77.8 & 77.8 & 77.8 & \\
\hline
\end{tabular}

HBV, hepatitis B virus; HCV, hepatitis C virus; NBNC, non-B, non-C hepatitis; AFP, alpha-fetoprotein; PIVKA-II, protein induced by vitamin K absence-II; EpCAM, epithelial cell adhesion molecule; POD, postoperative day; CD90, cluster of differentiation 90; MVI, microvascular invasion; NA, not available; mTORi, mammalian target of rapamycin inhibitor.

*Statistically significant, $p<0.05$.

on postoperative day 7 samples was higher in HCCs with CD90 expression than in those without $(\mathrm{p}=0.011)$. This difference was not identified preoperative and on postoperative day 1 samples (all $\mathrm{p}<0.05$ ). The mRNA levels of CD90 showed no significant difference between CD90+ HCCs and CD90- HCCs preoperative, on postoperative days 1 and 7 samples (Fig. 3D). Furthermore, CD90 expression was more frequent in EpCAM+ HCCs compared to EpCAM- HCCs. The status of EpCAM and/or CD90 expression were classified as (1) EpCAM+ and CD90+, (2) EpCAM+ and CD90-, (3) EpCAM- and CD90+, or (4) EpCAM- and CD90-. The recurrence rate was not shown any differences among these four groups (Fig. 3B).

\section{3. mRNA levels of stemness- and EMT-related genes in HCC recurrence after LDLT}

The expression levels of stemness-related genes (EpCAM, K19, and CD90) and EMT-related genes (SNAIL and TWIST) were assessed via RT-qPCR in CD45-depleted peripheral blood mononuclear cells of 25 patients preoperatively, on postoperative day 1 , and postoperative day 7 (Fig. 4).

The transcripts of EPCAM and $C D 90$ were relatively higher in HCC with recurrence than in HCC without recurrence; however, statistical significance was not reached (preoperative, postoperative day 1 , and postoperative day 3, all p>0.05) (Fig. 4). However, K19 mRNA levels did not exhibit any difference between the two groups. Similar to K19, the transcripts of SNAIL and TWIST did not show any differences between HCCs with and without recurrence.

\section{Prognostic factors for DFS in HCC after LDLT}

Univariate analysis showed that the level of pretransplant serum PIVKA-II $\geq 100 \mathrm{mAU} / \mathrm{mL}$ was a significant variable affecting DFS ( $\mathrm{p}=0.047)$, and EpCAM+ CTCs were associated with decreased DFS preoperatively $(\mathrm{p}=0.025)$ (Table 2, Fig. 5), but not on postoperative days 1 and 7. EpCAM+/CD90+ CTCs were associated with significantly shorter DFS preoperatively and at postoperative day 1 (both $\mathrm{p}=0.004$ ) (Table 2, Fig. 5). DFS was not significantly different according to the CD90 expression status of CTCs at any time point. For LT patients, any clinicopathological characteristics such as high pretransplant serum levels of AFP, Milan criteria, tumor size, number of tumors, Edmondson-Steiner grade, and post-transplantation usage of mTORi were not associated with DFS and overall survival (Fig. 5, Table 2).

Multivariate analysis using the Cox proportional hazards model revealed that preoperative PIVKA-II and postoperative day 1 EpCAM+/CD90+ CTCs act as independent risk factors for HCC recurrence (hazard ratio, 14.64; 95\% confidence interval, 1.08 to $198.20 ; \mathrm{p}=0.043$ and hazard ratio, 26.88; $95 \%$ confidence interval, 1.86 to 387.51 ; $\mathrm{p}=0.016$, respectively) (Table 3 ). The sensitivity, specificity, accuracy, positive predictive value, and negative predictive value for postoperative day 1 EpCAM+/CD90+ CTCs and pretransplant PIVKA-II levels for predicting HCC recurrence are shown in Table 4. Postoperative day $1 \mathrm{EpCAM+/}$ CD $90+$ CTCs $\geq 1$ has high specificity of $94.7 \%$. 

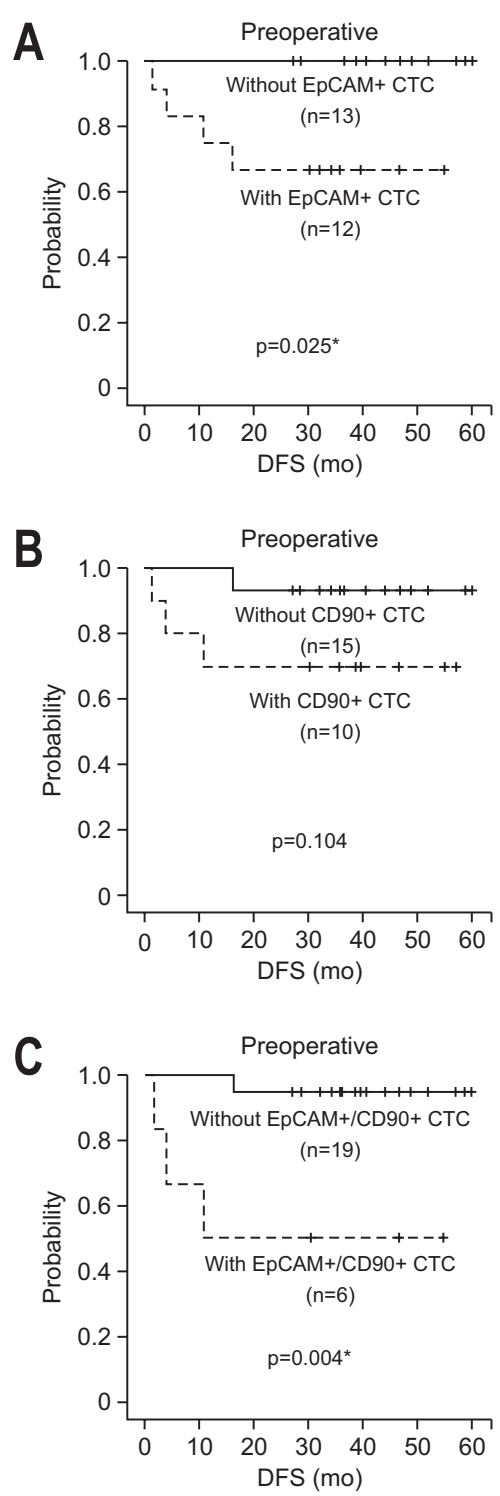
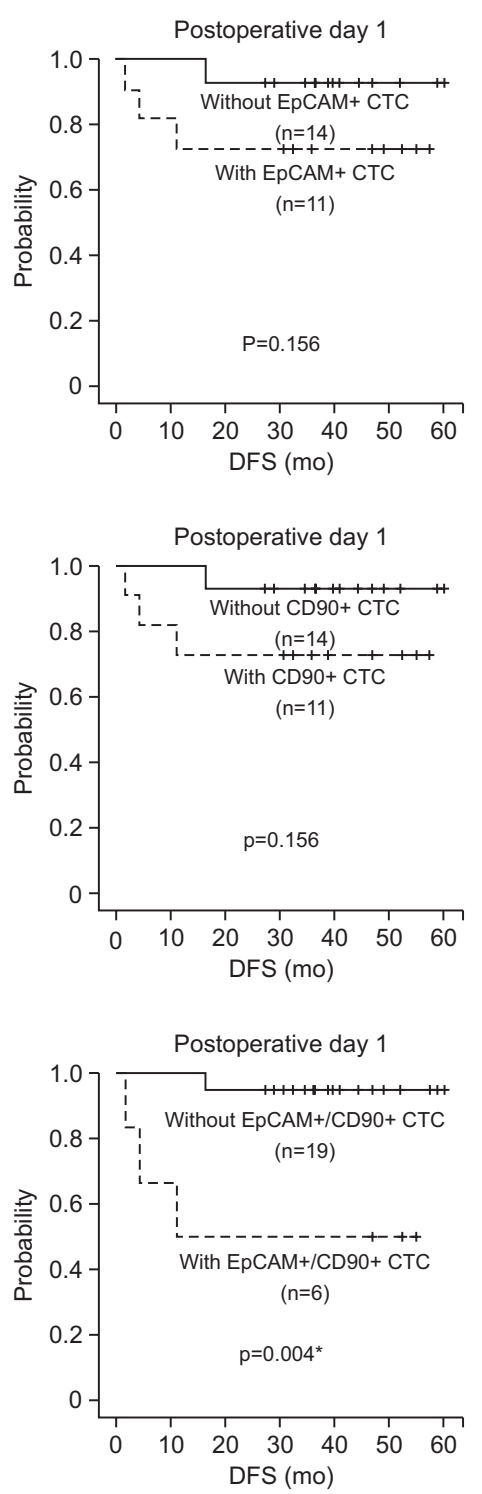
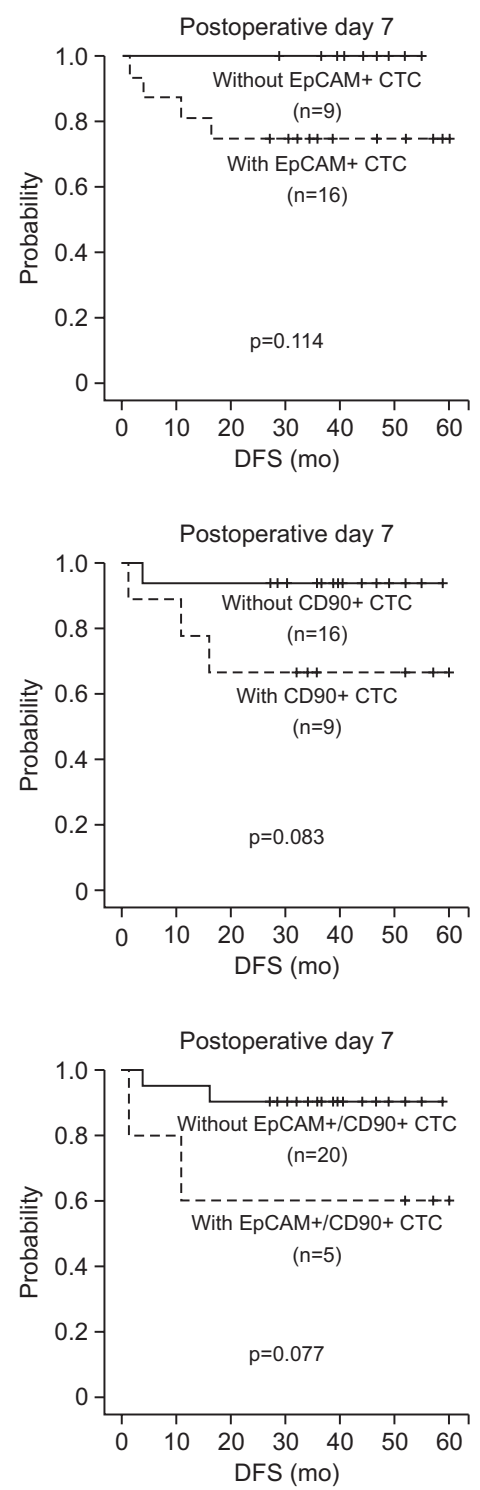

Fig. 5. Survival analysis plots for DFS in HCC according to the expression status of EpCAM and/or CD90 in CTCs. (A) Survival analysis plots for DFS in $\mathrm{HCC}$ according to the expression status of EpCAM in CTCs preoperatively and at postoperative days 1 and 7. (B) Survival analysis plots for DFS in HCC according to the expression status of CD90 in CTCs preoperatively and on postoperative days 1 and 7. (C) Survival analysis plots for DFS in HCC according to the coexpression status of EpCAM and CD90 in CTCs preoperatively and on postoperative days 1 and 7.

DFS, disease-free survival; HCC, hepatocellular carcinoma; EpCAM, epithelial cell adhesion molecule; CD90, cluster of differentiation 90; CTCs, circulating tumor cells. ${ }^{*} \mathrm{p}<0.05$.

Table 3. Multivariate Analysis for Hepatocellular Carcinoma Recurrence after Living Donor Liver Transplantation

\begin{tabular}{lcc}
\multicolumn{1}{c}{ Characteristics } & Hazard ratio $(95 \% \mathrm{CI})$ & p-value \\
\hline Pretransplant serum PIVKA-II $\geq 100 \mathrm{mAU} / \mathrm{mL}$ & $14.64(1.08-198.20)$ & 0.043 \\
POD 1 EpCAM and CD90 positive & $26.88(1.86-387.51)$ & 0.016 \\
\hline
\end{tabular}

$\mathrm{Cl}$, confidence interval; PIVKA-II, protein induced by vitamin K absence-II; POD, postoperative day; EpCAM, epithelial cell adhesion molecule; CD90, cluster of differentiation 90.

\section{DISCUSSION}

Several markers in HCC have been demonstrated to present stem cell-like properties in previous studies. ${ }^{17}$
Among such markers, EpCAM and CD90 were evaluated to isolate CTCs with cancer stemness, and the detection of HCC with these markers was strongly associated with HCC recurrence after surgical resection. ${ }^{9,10}$ With the ex- 
Table 4. Diagnostic Performance of CTCs and PIVKA-II Levels in the Prediction of Hepatocellular Carcinoma Recurrence

\begin{tabular}{lccccc}
\multicolumn{1}{c}{ Characteristics } & Sensitivity & Specificity & Accuracy & PPV & NPV \\
\hline POD 1 EpCAM+/CD90+ CTCs $\geq 1$ & $50.0(3 / 6)$ & $94.7(18 / 19)$ & $84.0(21 / 25)$ & $75.0(3 / 4)$ & $85.7(18 / 21)$ \\
Pretransplant serum PIVKA-II $\geq 100 \mathrm{mAU} / \mathrm{mL}$ & $37.5(3 / 8)$ & $94.1(16 / 17)$ & $76.0(19 / 25)$ & $75.0(3 / 4)$ & $76.2(16 / 21)$ \\
\hline
\end{tabular}

Data are presented as percentages (number/number).

CTC, circulating tumor cell; PIVKA-II, protein induced by vitamin K absence-II; POD, postoperative day; EpCAM, epithelial cell adhesion molecule; CD90, cluster of differentiation 90; PPV, positive predictive value; NPV, negative predictive value.

tension of these two studies and our previous research, ${ }^{11}$ we investigated whether the detection of CTCs with cancer stemness using FACs with EpCAM and CD90 markers could predict HCC recurrence after LDLT.

EpCAM, an epithelial cell adhesion molecule, is a wellestablished cancer stem cell in many other cancers as well as HCC. ${ }^{10,18}$ CD90 is also a cancer stem cell marker in HCC; however, it has features of vascular endothelial cells and is associated with a mesenchymal metastatic cancer stem cell marker. ${ }^{9}$ Yamashita et al. ${ }^{16}$ demonstrated that EpCAM+ and CD90+ HCC has a specific gene expression pattern, and has stem cell features with high capacity for metastasis to the lung in a xenotransplantation model. In this study, the detection of EpCAM+/CD90+ cells in peripheral blood on postoperative day 1 was associated with a higher rate of MVI in the primary HCC. The detected numbers of EpCAM+ CTCs and EpCAM+/CD90+ CTCs were significantly higher in patients with HCC recurrence than in those without recurrence preoperatively and on postoperative day 1. In agreement with previous studies, the detection of both EpCAM+ and CD90+ CTCs compared to EpCAM+ alone preoperatively and at postoperative day 1 was found to be more associated with HCC recurrence after LDLT in our study. The detected number of EpCAM+ and CD90+ CTCs showed a positive correlation with the mRNA levels of these markers in peripheral blood. However, the mRNA levels of EpCAM, K19, and CD90 and EMT-related genes (SNAIL and TWIST) were not associated with HCC recurrence after LDLT.

Potential correlations involving EpCAM protein expression in HCC tissues, the detected numbers of EpCAM+ CTCs, and the levels of EPCAM mRNA in peripheral blood were also investigated. In our study, HCCs with EpCAM+ protein expression were found to have significantly higher numbers of EpCAM+ CTCs and higher EpCAM mRNA levels during the perioperative period. These results indicated that EpCAM+ CTCs mainly originated from EpCAM+ HCC tumors. However, the number of EpCAM+ CTCs and EpCAM+/CD90+ CTCs on postoperative day 7 showed less correlation with HCC recurrence compared to those seen preoperatively and at postoperative day 1 . The detection of EpCAM+ CTCs and EpCAM+/CD90+ CTCs was also associated with $\mathrm{HCC}$ recurrence only preopera- tively and on postoperative day 1 . These results might be attributed to the fact that these HCC cancer stem cell markers are also those of normal hepatocyte progenitor cells, which play a major role in liver regeneration, and that the grafted liver is actively regenerated on postoperative day $7 .{ }^{19-22}$

The prognostic impact of EpCAM+/CD90+ CTC detection on the preoperative day in this study can be incorporated into clinical practice because liquid biopsy is an emerging method to analyze tumor biology in a minimally invasive manner, and has a potential impact on LT candidate selection and postoperative monitoring. ${ }^{12,14}$ The selection criteria for LT candidates among HCC patients have evolved from classic morphological to biological criteria, which include tumor markers and molecular biomarkers. However, most molecular biomarkers are investigated and established in tumor tissues, and tissue biopsy is required for preoperative clinical use. FACs for the detection of CTCs is a reliable high-throughput technology with objectivity and high efficiency for detecting rare cell population in fluids. ${ }^{23}$ However, this method requires a large number of cells for accurate quantitation and there is no capacity for morphological analysis without additional instruments such as fluorescent microscope. ${ }^{24-26}$ Furthermore, it has been also suggested that FACs may have limited sensitivity for CTC analysis in human blood samples if one or two cells were contained in the samples. ${ }^{27}$ To overcome this limitation, we increased the amount of blood used for FACs analysis to $10 \mathrm{~mL}$, and proceeded with RT-qPCR as well as FACs. The number of EpCAM+ CTCs were positively correlated with mRNA level of EpCAM and that of CD90+ CTCs was shown positive correlation with mRNA level of CD90. Isolation of CTCs represents one of the efforts to identify the direct cause of HCC tumor recurrence, and can be more useful for selecting optimal candidates for LT in HCC patients who fall outside of accepted clinical criteria, or in patients with down-staging treatments for advanced HCC. In multivariate analysis, the detection of EpCAM+/CD90+ CTCs at postoperative day 1 and pretransplant serum PIVKA-II $\geq 100 \mathrm{mAU} / \mathrm{mL}$ were found to be independent prognostic factors for HCC recurrence after LDLT in this study, which can be used to select highrisk LT candidates and optimal post-transplant immunosuppressive drugs. A recent meta-analysis demonstrated 
that postoperative immunosuppression based on mTORi administration improved DFS and overall survival compared with that based on $\mathrm{CNI} .{ }^{28}$ mTORi without CNI may be clinically recommended in these patients with higher risk of HCC recurrence after LT; however, further welldesigned studies are required for additional solid evidence.

This study had several limitations. Even though this study was designed in a prospective way, the number of study subjects and patients with HCC recurrence was small, which might produce the question about the reliability of the results by statistical analysis using the Cox proportional hazard model. In addition, conventional wellknown prognostic factors such as tumor size, number, MVI, and tumor histologic grade were not associated with HCC recurrence after LDLT in this study, which may mean that this study cohort might not represent all transplant recipients, and these results might not be generalizable in clinical practice. However, despite the small study population and events, the detection of EpCAM+/CD90+ CTCs before surgery and at postoperative day 1 aided in predicting HCC recurrence after LDLT in this study. This result is in agreement with the findings of previous studies showing that circulating cancer stem cells are directly responsible for metastasis and recurrence, and are more powerful in predicting tumor recurrence compared with conventional clinicopathological prognostic factors. ${ }^{2,3,14,29-33}$ Therefore, the preliminary results of this study should be validated in a large-scale multicenter study.

In conclusion, pretransplant serum PIVKA-II levels and the detection of EpCAM+ CTCs preoperatively and EpCAM+/CD90+ CTCs preoperatively and on postoperative day 1 could predict HCC recurrence after LDLT. These findings can be used to select optimal candidates for LT in patients with HCC, especially those at higher risk of recurrence, and can guide tailored postoperative monitoring and immunosuppression. However, due to the small size of the study cohort and the events, these preliminary results should be validated in a large prospective study.

\section{CONFLICTS OF INTEREST}

Y.N.P. is an editorial board member of the journal but was not involved in the peer reviewer selection, evaluation, or decision process of this article. No other potential conflicts of interest relevant to this article were reported.

\section{ACKNOWLEDGEMENTS}

This research was supported by a faculty research grant from Yonsei University College of Medicine (numbers: 6-2016-0065 and 6-2016-0039) and a National Research Foundation of Korea (NRF) grant funded by the Korea government (MSIP) (number: NRF-2017R1A2B1010542, G.H.C.) and by the Basic Science Research Program through the NRF (number: NRF-2020R1A2B5B01001646), and by the Bio and Medical Technology Development Program of the NRF funded by the Ministry of Science and ICT (MSIT) (number: NRF-2016M3A9D5A01952416, Y.N.P.).

\section{AUTHOR CONTRIBUTIONS}

Conceptualization: H.S.H., J.E.Y., G.H.C., Y.N.P. Data curation: H.S.H., J.E.Y., G.H.C. Formal analysis: H.S.H., J.E.Y., G.H.C. Methodology: J.E.Y., G.H.C., Y.N.P. Visualization: H.S.H., J.E.Y. Sample collection: D.H.H., J.S.C., J.G.L., D.J.J., M.S.K., S.I.K., G.H.C. Funding acquisition: G.H.C., Y.N.P. Writing - original draft: H.S.H., J.E.Y. Writing - review \& editing: G.H.C., Y.N.P. Approval of final manuscript: all authors.

\section{ORCID}

Hyeo Seong Hwang https://orcid.org/0000-0002-0339-1524 Jeong Eun Yoo https://orcid.org/0000-0001-9990-279X Dai Hoon Han https://orcid.org/0000-0003-2787-7876 Jin Sub Choi https://orcid.org/0000-0002-6467-6494 Jae Geun Lee https://orcid.org/0000-0002-6722-0257 Dong Jin Joo https://orcid.org/0000-0001-8405-1531 Myoung Soo Kim https://orcid.org/0000-0002-8975-8381 Soon Il Kim https://orcid.org/0000-0002-0783-7538 Gi Hong Choi https://orcid.org/0000-0002-1593-3773 Young Nyun Park https://orcid.org/0000-0003-0357-7967

\section{SUPPLEMENTARY MATERIALS}

Supplementary materials can be accessed at https://doi. org/10.5009/gnl210162.

\section{REFERENCES}

1. Mazzaferro V, Regalia E, Doci R, et al. Liver transplantation for the treatment of small hepatocellular carcinomas in patients with cirrhosis. N Engl J Med 1996;334:693-699.

2. Mazzaferro V, Sposito C, Zhou J, et al. Metroticket 2.0 model for analysis of competing risks of death after liver transplantation for hepatocellular carcinoma. Gastroenterology 
2018;154:128-139.

3. Tanaka F, Yoneda K, Kondo N, et al. Circulating tumor cell as a diagnostic marker in primary lung cancer. Clin Cancer Res 2009;15:6980-6986.

4. Aceto N, Bardia A, Miyamoto DT, et al. Circulating tumor cell clusters are oligoclonal precursors of breast cancer metastasis. Cell 2014;158:1110-1122.

5. Tsai WS, Chen JS, Shao HJ, et al. Circulating tumor cell count correlates with colorectal neoplasm progression and is a prognostic marker for distant metastasis in non-metastatic patients. Sci Rep 2016;6:24517.

6. Reya T, Morrison SJ, Clarke MF, Weissman IL. Stem cells, cancer, and cancer stem cells. Nature 2001;414:105-111.

7. Ji J, Wang XW. Clinical implications of cancer stem cell biology in hepatocellular carcinoma. Semin Oncol 2012;39:461472.

8. Yang W, Yan HX, Chen L, et al. Wnt/beta-catenin signaling contributes to activation of normal and tumorigenic liver progenitor cells. Cancer Res 2008;68:4287-4295.

9. Yang ZF, Ho DW, Ng MN, et al. Significance of CD90+ cancer stem cells in human liver cancer. Cancer Cell 2008;13:153-166.

10. Terris B, Cavard C, Perret C. EpCAM, a new marker for cancer stem cells in hepatocellular carcinoma. J Hepatol 2010;52:280-281.

11. Choi GH, Kim GI, Yoo JE, et al. Increased expression of circulating cancer stem cell markers during the perioperative period predicts early recurrence after curative resection of hepatocellular carcinoma. Ann Surg Oncol 2015;22 Suppl 3:S1444-S1452.

12. Xue F, Shi S, Zhang Z, et al. Application of a novel liquid biopsy in patients with hepatocellular carcinoma undergoing liver transplantation. Oncol Lett 2018;15:5481-5488.

13. Wang S, Zheng Y, Liu J, Huo F, Zhou J. Analysis of circulating tumor cells in patients with hepatocellular carcinoma recurrence following liver transplantation. J Investig Med 2018;66:1-6.

14. von Felden J, Villanueva A. Role of molecular biomarkers in liver transplantation for hepatocellular carcinoma. Liver Transpl 2020;26:823-831.

15. Kumar A, Bhanja A, Bhattacharyya J, Jaganathan BG. Multiple roles of CD90 in cancer. Tumour Biol 2016;37:1161111622.

16. Yamashita T, Honda M, Nakamoto Y, et al. Discrete nature of EpCAM+ and CD90+ cancer stem cells in human hepatocellular carcinoma. Hepatology 2013;57:1484-1497.

17. Yamashita T, Wang XW. Cancer stem cells in the development of liver cancer. J Clin Invest 2013;123:1911-1918.

18. Yamashita T, Ji J, Budhu A, et al. EpCAM-positive hepatocellular carcinoma cells are tumor-initiating cells with stem/ progenitor cell features. Gastroenterology 2009;136:10121024.
19. Tao Y, Wang M, Chen E, Tang H. Liver regeneration: analysis of the main relevant signaling molecules. Mediators Inflamm 2017;2017:4256352.

20. Hu M, Li S, Menon S, et al. Expansion and hepatic differentiation of adult blood-derived CD34+ progenitor cells and promotion of liver regeneration after acute injury. Stem Cells Transl Med 2016;5:723-732.

21. Tsui YM, Chan LK, Ng IO. Cancer stemness in hepatocellular carcinoma: mechanisms and translational potential. $\mathrm{Br}$ J Cancer 2020;122:1428-1440.

22. Zhang L, Theise N, Chua M, Reid LM. The stem cell niche of human livers: symmetry between development and regeneration. Hepatology 2008;48:1598-1607.

23. Lopresti A, Malergue F, Bertucci F, et al. Sensitive and easy screening for circulating tumor cells by flow cytometry. JCI Insight 2019;5:e128180.

24. Kuckuck FW, Edwards BS, Sklar LA. High throughput flow cytometry. Cytometry 2001;44:83-90.

25. Goodale D, Phay C, Postenka CO, Keeney M, Allan AL. Characterization of tumor cell dissemination patterns in preclinical models of cancer metastasis using flow cytometry and laser scanning cytometry. Cytometry A 2009;75:344-355.

26. Ho A, Haas R, Champlin RE. Detection of infrequent cells in blood and bone marrow by flow cytometry. New York: Marcel Dekker Inc., 2000.

27. Bocsi J, Varga VS, Molnár B, Sipos F, Tulassay Z, Tárnok A. Scanning fluorescent microscopy analysis is applicable for absolute and relative cell frequency determinations. Cytometry A 2004;61:1-8.

28. Grigg SE, Sarri GL, Gow PJ, Yeomans ND. Systematic review with meta-analysis: sirolimus- or everolimus-based immunosuppression following liver transplantation for hepatocellular carcinoma. Aliment Pharmacol Ther 2019;49:12601273.

29. Yin LC, Luo ZC, Gao YX, Li Y, Peng Q, Gao Y. Twist expression in circulating hepatocellular carcinoma cells predicts metastasis and prognoses. Biomed Res Int 2018;2018:3789613.

30. Fan ST, Yang ZF, Ho DW, Ng MN, Yu WC, Wong J. Prediction of posthepatectomy recurrence of hepatocellular carcinoma by circulating cancer stem cells: a prospective study. Ann Surg 2011;254:569-576.

31. Sun YF, Xu Y, Yang XR, et al. Circulating stem cell-like epithelial cell adhesion molecule-positive tumor cells indicate poor prognosis of hepatocellular carcinoma after curative resection. Hepatology 2013;57:1458-1468.

32. Qi LN, Xiang BD, Wu FX, et al. Circulating tumor cells undergoing EMT provide a metric for diagnosis and prognosis of patients with hepatocellular carcinoma. Cancer Res 2018;78:4731-4744.

33. Ou H, Huang Y, Xiang L, et al. Circulating tumor cell phenotype indicates poor survival and recurrence after surgery for hepatocellular carcinoma. Dig Dis Sci 2018;63:2373-2380. 